\title{
Factors Contributing to Missed Opportunities and Incomplete Vaccination of Children: A Focus on Mothers in Rumbek Centre County of Lakes State South Sudan
}

\author{
Ebenezer Obi Daniel ${ }^{1}$, , Paul Olaiya Abiodun ${ }^{1}$, Gabriel Omoniyi Ayeni ${ }^{1}$, Olayinka Victor Ojo ${ }^{1}$, \\ John Biar Anyieth ${ }^{1}$, Oladapo Michael Olagbegi ${ }^{2}$ \\ ${ }^{1}$ Department of Public Health, Texila American University, Georgetown, Guyana \\ ${ }^{2}$ Department of Physiotherapy, University of Kwazulu-Natal Westville Campus, Durban, South Africa
}

Email address:

dannypressy@yahoo.com (E. O. Daniel)

${ }^{*}$ Corresponding author

\section{To cite this article:}

Ebenezer Obi Daniel, Paul Olaiya Abiodun, Gabriel Omoniyi Ayeni, Olayinka Victor Ojo, John Biar Anyieth, Oladapo Michael Olagbegi. Factors Contributing to Missed Opportunities and Incomplete Vaccination of Children: A Focus on Mothers in Rumbek Centre County of Lakes State South Sudan. World Journal of Public Health. Vol. 4, No. 3, 2019, pp. 47-54. doi: 10.11648/j.wjph.20190403.11

Received: July 21, 2019; Accepted: August 13, 2019; Published: August 26, 2019

\begin{abstract}
Vaccine Preventable Diseases (VPDs) have been proven to be easily mitigated among the infants/children if the target population is effectively mobilized to receive the vaccines especially at the appropriate ages. The role played by mothers/guides in ensuring their wards get vaccinated appropriately cannot be over-emphasized. Their knowledge and attitude towards immunization can either promote or retard the possibility for missed opportunity and incomplete vaccination of this vulnerable and helpless population. The main objective of this study was to determine the knowledge and attitude of the mothers/guides and to determine the predicting factors contributing to the missed opportunities and incomplete vaccination in Rumbek Centre County Lakes State of South Sudan. The study was carried out at the Rumbek State Hospital and Matangai Primary Health Care Centre, both in Rumbek Centre County of Lakes State in South Sudan. A descriptive cross sectional study of mothers/guides attending immunization clinics of both health units was carried out. Inclusion of participants was done by simple random sampling. Data was obtained through the use of structured, self-administered questionnaire. Summated scores were used to grade respondents' knowledge and attitude towards immunization. Data analysis was done using the Statistical package for Social Science (SPSS) version 21. Data were presented using descriptive statistics of frequencies, percentages, and pie charts. Inferential statistics of Chi-square was used to test for associations between various socio-demographic variables and the knowledge and attitude of mothers/guides towards immunization. A considerably high proportion of mothers/guides (72.1\%) have good knowledge on immunization with $27.9 \%$ of them having poor knowledge on immunization. Slightly above average $(52.9 \%)$ of the mothers/guides have good attitude towards immunization while a fairly large proportion (47.1\%) of them have poor attitude towards immunization. Marital status, level of education, occupation and number of children were all found to have statistically significantly associated $(\mathrm{P}<0.05)$ with the mothers'/guides' knowledge on immunization. This study further revealed that Marital status, religion, level of education and occupation have statistical significant association $(\mathrm{P}<0.05)$ with the attitudes of the mothers/guides towards immunization. Vaccination compliance analysis in this study revealed a downward trend along the various vaccines/indicators based on age and vaccines received by each respondent's child. Among the suggested recommendations include improved immunization health education for mothers/guides, training and re-training of vaccinators/health workers, effective tracking of defaulters and concerted efforts towards lasting peace in South Sudan.
\end{abstract}

Keywords: Vaccination, Missed Opportunities, Mothers/Guides, Knowledge and Attitude 


\section{Introduction}

Immunization is a most powerful and cost-effective weapon of disease prevention, yet it remains underutilized in developing countries. Today children aged less than five years die and become disabled with each passing minutes because of non-availability of immunization [1]. Diseases such as neonatal tetanus and poliomyelitis which have been eliminated in most of the developed countries continue to take a heavy toll in developing countries; measles and whooping cough are killer diseases particularly in children less than six months of age. Diphtheria and TB can be added to the list [2].

During the 1950s and 1960s, most developed countries had elements of immunization services, they were available in small-scale offered periodically. The vaccine used was not always potent and also most did not complete their immunization schedule. Recent trend estimate that pentavalent immunization is $83 \%$. But 22.6 million children did not receive pentavalent 3 in 2012 compared to 22.3 million in 2011 [3]. Although the recent trend related to global vaccination coverage is positive with 120 countries reaching $90 \%$ pentavalent 3 , the total number children who died from disease preventable by vaccine currently by WHO is 1.5 million. Nearly $17 \%$ of all death in children under 5 are vaccine preventable. In 2012, the global coverage of polio was 845 and the reported number of confirmed cases was 293 in the same year. However, pockets under vaccination continue to persist in Sub-Saharan Africa. In South Sudan, the percentage of fully immunized children under the age of 5 was at $77 \%$ [4].

The recommended vaccination is at $77.4 \%$, however, the program varies from 48.3 in North Eastern Province to $85.8 \%$ in the Central province [5]. These geographical inequalities in immunization coverage reflect the variation across different regions. Some of the factors have been found to contribute to missed opportunities and incomplete vaccination are (a) maternal level of education, (b) accessibility to health facility, (c) sick guardian/sick child, (d) conflicting priorities (e) religion and (f) attitude of health workers [6].

In 1974 more than $5 \%$ of the world's infant was fully immunized. By 2005 global coverage with the Third dose of pentavalent vaccines was $79 \%$ but many children especially those living in poor countries still were not reached. In 1974, the United Nations child fund (UNICEF) developed the global immunization vision and strategic goals. It is very important for all countries to achieve $90 \%$ national DPT3 coverage and at least $80 \%$ in every district or equal administrative area. The goals of the EPI was to; sustain immunization coverage, reduce morbidity and mortality from preventable diseases, ensure access to vaccines of assured quality for every person eligible for immunization, introduce new vaccines for the entire eligible population in the national program, ensure capacity for surveillance and monitoring for all countries that will have developed capacities at all level to conduct case-based surveillance vaccine-preventable disease and strengthen system and ensure sustainability [7].

In 2010, 130 countries $(67 \%)$ had achieved $90 \%$ pentavalent 3 and estimated $85 \%$ of infants worldwide had received at least 3 doses of pentavalent, however, 19.3 million children were not fully vaccinated and remained at risk for Diphtheria, tetanus, pertussis, hepatitis B, and Haemophilus influenza. Approximately $50 \%$ of these children live in India, Nigeria, and DRC. In 2010, estimated global pentavalent coverage among children age less 12 months was $85 \%$ representing 109.4 million immunized children, slightly higher than the estimated coverage in 2009 (82\%) pentavalent 3 coverage in $/ 2010$ ranged from $77 \%$ in Africa and Southeast Asia WHO regions to $98 \%$ in western Pacific and European regions 50 (30\%) member states reported achieving a 2 nd global immunization vision and strategy target of equal or more then $>80 \%$ pentavalent [8].

The World Health Organization estimated that 83\% (111 million) of infants worldwide were vaccinated with 3 doses of pentavalent 3. The report stated that the number of countries 165 against 164 countries in 2011. The report also said 131 countries reached over $90 \%$ or more immunization coverage with pentavalent 3 vaccines was in 2012 compared to 128 countries in 2011 [9]. According to Trépo et al., 2014 [10], Hepatitis $\mathrm{B}$ vaccine for infants was introduced worldwide in 181 countries by the end of 2012. They stated further that Global coverage with 3 doses of Hepatitis B vaccine was at $79 \%$ and as high as $91 \%$ in western Pacific and America. They also reported that coverage in south-east Asia region reached $72 \%$ in 2012 up in 2012 from 565 in 2011.

Hemophilus Influenza type B vaccine was introduced in 184 countries by 2012 up from 177 countries in 2011. The global coverage with 3 doses of Hemophilus vaccine was estimated at $45 \%$ in 2012. Yellow fever vaccine was introduced in routine infant immunization programs in 2011 in 36 countries and territories out of 48 at risk for yellow fever in Africa and America. The pneumococcal vaccine was introduced in 2011 in 73 countries including Kenya, by the end of 2012. Despite substantial progress, the world is still falling short of the MDG 4; child mortality target. Preventable diseases are the main causes of under-five deaths in children and appropriate actions should be taken. The MDG 4 is one of the goals which were to reduce under-5 mortality rates by $2 / 3$ "between" (1990-20150, while 6.6 million children under five died in 2012 . Almost $75 \%$ of all childhood deaths are attributable to just six conditions: neonatal causes, pneumonia, diarrhoea, malaria, HIV, and measles [11].

In view of the above highlights, and to bridge the existing knowledge gap in the study area, the aim of this study was to determine the knowledge and attitude of the mothers/guides and to determine the predicting factors contributing to the missed opportunities and incomplete vaccination in Rumbek Centre County Lakes State of South Sudan. 


\section{Method}

A cross-sectional descriptive study design was employed in this study. The study was conducted in Rumbek Centre County of Lakes State of South Sudan. Two health facilities were used as the study sites namely Rumbek State Hospital (RSH) and Matangai Primary Health Care Centre (PHCC). The participants were 105 mothers/guides of infants and children attending immunization clinic that has lived in Rumbek Centre County for at least four months for easier monitoring. They were recruited through simple random sampling into the study.

Data were collected using structured questionnaire consisting of four sections A to D. Section A consists of socio-demographic variables, section B consists of questions on knowledge of mothers/guardians on immunization; section $\mathrm{C}$ consists of questions on attitude of mothers/guardians towards immunization and section D consist of vaccine compliance check-list for their children. Two research assistants were recruited and trained for the purpose of data collection and language interpretation was done for all mothers/guides who could not read English.

An approval to conduct the study was obtained from the County Health Department (CHD). Each Participant was informed in writing, with full explanation of the content of the questionnaire and the purpose of the study. They were also guaranteed the confidentiality of whatever information given by them in the study tool. A statement of informed consent was clearly written on the questionnaire, which was signed by the respondents before filling the questionnaire.

Data collected were analysed using SPSS software version 21.0. The data were checked for accuracy and completeness. On completion of data entry, data cleaning was carried out to identify any mistakes that might occur during data entry. Descriptive statistics were used to summarize data into frequencies, graphs and tables. Chi-square was used to test for association between various socio-demographic factors and knowledge and attitude of mothers/guardians.

\section{Results}

One hundred and five (105) questionnaires were distributed for data collection from the mothers/guides while one hundred and four (104) were fully responded to, and returned. This implies ninety-nine per cent $(99 \%)$ response rate. The various socio-demographic characteristics of the respondents were shown in table 1 . Mothers of age bracket 21-30 formed the largest number of participants 50 (48.1\%) while only $4(3.8 \%)$ were between $41-50$. Approximately ninety-six per cent $(96 \%)$ of the respondents are married, while $94 \%$ are Christians. Very large proportion of the respondents $(84.6 \%)$ has no formal education with only $2.9 \%$ having education up to secondary level. Occupational distribution of the respondents revealed that over half $(54.8 \%)$ are house wives, $38.5 \%$ are farmers and only $1 \%$ work as health care giver.

A fairly appreciable proportion of respondents (26.9\%) have at least three children, and $15.4 \%$ have four children. An outlier of $1 \%$ of the respondents has eleven children.

Table 1. Socio-demographic characteristics of mothers/guides.

\begin{tabular}{|c|c|c|}
\hline VARIABLE & FREQUENCY & PERCENTAGE \\
\hline \multicolumn{3}{|l|}{ AGE } \\
\hline $15-20$ & 24 & 23.1 \\
\hline $21-30$ & 50 & 48.1 \\
\hline $31-40$ & 26 & 25.0 \\
\hline $41-50$ & 4 & 3.8 \\
\hline Total & 104 & 100.0 \\
\hline \multicolumn{3}{|l|}{ MARITAL STATUS } \\
\hline Single & 4 & 3.8 \\
\hline Married & 100 & 96.2 \\
\hline Total & 104 & 100.0 \\
\hline \multicolumn{3}{|l|}{ RELIGION } \\
\hline Christianity & 98 & 94.2 \\
\hline Islam & 6 & 5.8 \\
\hline Total & 104 & 100.0 \\
\hline \multicolumn{3}{|c|}{ LEVEL OF EDUCATION } \\
\hline No formal education & 88 & 84.6 \\
\hline Primary education & 13 & 12.5 \\
\hline Secondary education & 3 & 2.9 \\
\hline Total & 104 & 100.0 \\
\hline \multicolumn{3}{|l|}{ OCCUPATION } \\
\hline Housewife & 57 & 54.8 \\
\hline Farming & 40 & 38.5 \\
\hline Teaching & 1 & 1.0 \\
\hline Healthcare & 1 & 1.0 \\
\hline Business & 5 & 4.8 \\
\hline Total & 104 & 100.0 \\
\hline \multicolumn{3}{|c|}{ NUMBER OF CHILDREN } \\
\hline 1.00 & 12 & 11.5 \\
\hline 2.00 & 24 & 23.1 \\
\hline 3.00 & 28 & 26.9 \\
\hline 4.00 & 16 & 15.4 \\
\hline 5.00 & 6 & 5.8 \\
\hline 6.00 & 12 & 11.5 \\
\hline 7.00 & 5 & 4.8 \\
\hline 11.00 & 1 & 1.0 \\
\hline Total & 104 & 100.0 \\
\hline
\end{tabular}

Knowledge of mothers/guides on immunization

Figure 1 below shows the knowledge distribution of the mothers/guide on immunization in Rumbek Centre County. Approximately seventy-two per cent (72\%) have good knowledge while approximately twenty-eight (28\%) have poor knowledge on immunization.

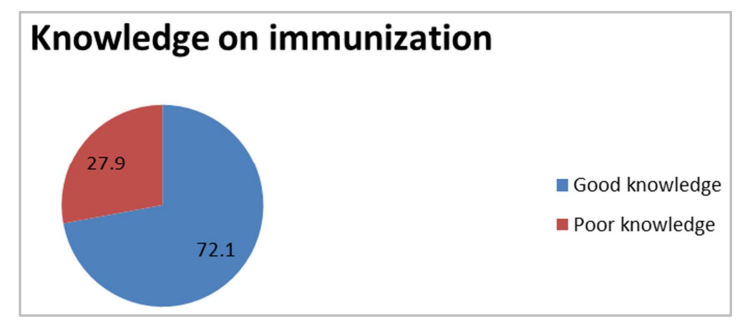

Figure 1. Percentage distribution of knowledge of mothers/guide towards immunization.

Attitudes of mothers/guides towards immunization

The attitude percentage distribution of the respondents is represented in the figure 2 below. On the overall, slightly above half of the respondents $(52.9 \%)$ have good attitudes 
and $47.1 \%$ have poor attitude towards immunization.

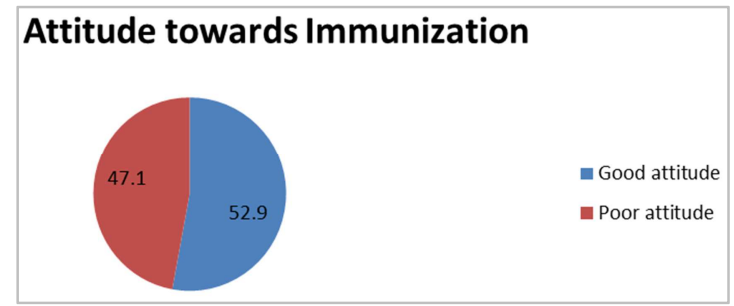

Figure 2. Percentage distribution of attitude of mothers/guides towards immunization.

Association between mothers'/guides' knowledge and socio-demographic variables

The association between the knowledge and the sociodemographic variables of the respondents is shown in table 2. Marital status, level of education, occupation and number of children were found to have statistically significant association with the knowledge of the mothers/guides on immunization $(\mathrm{P}<0.05)$.

Table 2. Chi-Square analysis showing association between mothers'/guides knowledge on immunization and socio-demographic characteristics of the respondents.

\begin{tabular}{llll}
\hline & $\chi^{2}$ value & Df & p value \\
\hline Age & 2.949 & 3 & 0.400 \\
Marital Status & 4.592 & 1 & $0.032^{* *}$ \\
Religion & 0.094 & 1 & 0.759 \\
Level of Education & 5.109 & 2 & $0.038^{* *}$ \\
Occupation & 11.670 & 4 & $0.020^{* *}$ \\
Number of Children & 16.904 & 7 & $0.018^{* *}$ \\
\hline
\end{tabular}

** Significant at $\mathrm{P}<0.05$.

Association between mothers'/guides' attitude and sociodemographic variables

Table 3 presents the chi-square analysis of the mothers'/guides' attitudes and their socio-demographic variables. Marital status, Religion, Level of education, and occupation are all found to have statistically significant association with the attitude of the mothers/guides towards immunization $(\mathrm{P}<0.05)$.

Table 3. Chi-Square analysis showing association between mothers'/guides' Attitude towards immunization and socio-demographic characteristics of the respondents.

\begin{tabular}{llll}
\hline & $\boldsymbol{\chi}^{2}$ value & df & p value \\
\hline Age & 3.820 & 3 & 0.282 \\
Marital Status & 4.669 & 1 & $0.031^{* *}$ \\
Religion & 7.147 & 1 & $0.008^{* *}$ \\
Level of Education & 9.363 & 2 & $0.009^{* *}$ \\
Occupation & 15.243 & 4 & $0.004^{* *}$ \\
Number of Children & 5.866 & 7 & 0.555 \\
\hline
\end{tabular}

** Significant at $\mathrm{P}<0.05$.

Vaccine compliance

The various vaccines' compliance (using age as the reference point and guide) of each respondent's child was verified from the child health card brought to the immunization clinic by the mother/guide. The four major vaccines' compliance of the respondents' children received by children in South Sudan for this study were as shown in figures $3,4,5$ and 6 .

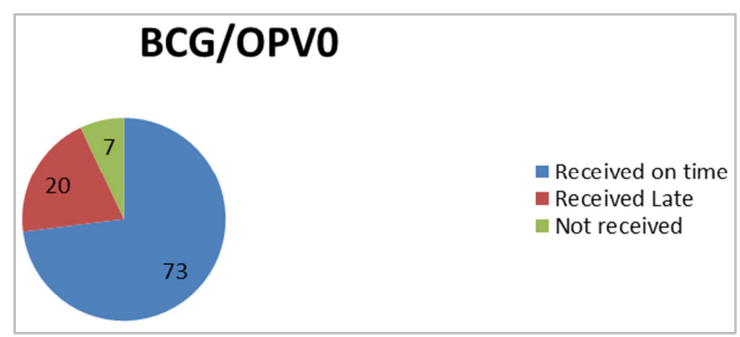

Figure 3. Percentage distribution of vaccine compliance on BCG/OPVO vaccines for the respondents' children.

Figure 3 above revealed that of all the children due by age for $\mathrm{BCG}$ and OPV0 vaccines, $73 \%$ of them received $\mathrm{BCG}$ and OP0 at the right time (ideally at birth), $20 \%$ received the two vaccines late and $7 \%$ of them did not receive as at the study period.

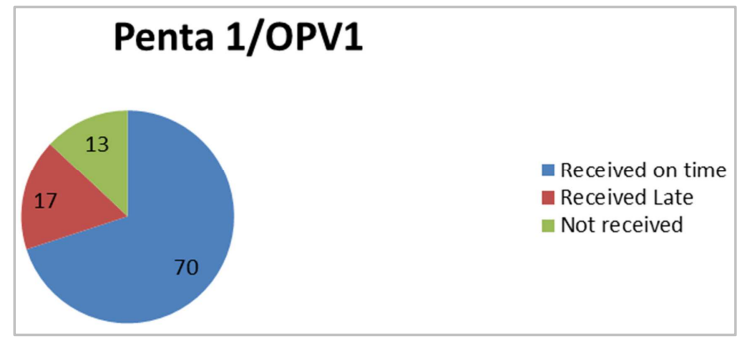

Figure 4. Percentage distribution of vaccine compliance on Penta1/OPV1 vaccines for the respondents' children.

The figure 4 above showed that among all the children due for Penta1 and OPV1 vaccines, $70 \%$ of the children received the vaccines at the right time of six weeks of age, $17 \%$ received the vaccines at a later period and $13 \%$ did not receive the two vaccines as at the study period.

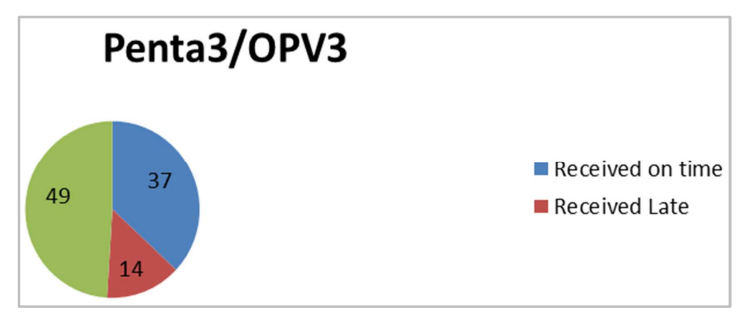

Figure 5. Percentage distribution of vaccine compliance on Penta3/OPV3 vaccines for the respondents' children.

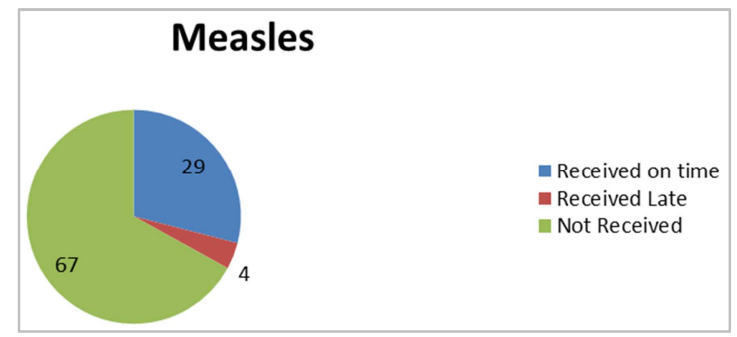

Figure 6. Percentage distribution of vaccine compliance on Measles vaccine for the respondents' children. 
From figure 5 above, it can be deduced that, $37 \%$ of all the children due for by age for Penta3 and OPV3 vaccines received them at the right time of ten weeks, $14 \%$ of them received the vaccines at a later date while almost half (49\%) had not received the two vaccines as at the study period.

The inference from figure 6 is, as at the study period, only $29 \%$ of the respondents' children due by age for Measles vaccine received it at the right time (ideally at nine months), $4 \%$ of them received the vaccine late and more than two-third $(67 \%)$ of them had not received the vaccines.

\section{Discussion}

\subsection{Socio-demographic Characteristics}

In this study, 104 out of 105 mothers/guides responded to the questionnaire making an appreciable response rate of $99 \%$. Mothers/guides between the age bracket of 21-30 represent the highest number of participants (48.1\%), while only $4(3.8 \%)$ were between $41-50$ ages. Ninety six per cent $(96 \%)$ of the respondents are married, and $94 \%$ are Christians. Some of the reasons responsible for the foregoing is tantamount to the fact that early marriage is still rampant in South Sudan in general and is more conspicuous among the Dinkas, the largest tribe in the country with a competitive kind of attitude among the families to get their daughters married 'on time'.

A conspicuously proportion of mothers/guides (84.6\%) has no formal education with only a negligible proportion of $2.9 \%$ having education up to secondary level. The reason for this is connected to the previously stated reason as marriage is seen as a more acceptable achievement in the study area with evidence of many school drop-outs among the girls, consequent to the perception of giving them out in marriage anytime the suitor comes around. Hence, there is always a high probability of getting many married women without formal education. Occupational distribution of the respondents revealed that over half $(54.8 \%)$ are house wives $38.5 \%$ are farmers and only ${ }^{`} 1 \%$ work as health care giver. The glaring explanation for this is high proportion of respondents being house wives is as a result of their level of education which is very low or even at zero level. In order to make ends meet, some of them tends towards agriculture (most times subsistence farming).

Most respondents $(26.9 \%)$ have at least three children, and $15.4 \%$ have four children. One per cent $(1 \%)$ of the respondents has eleven children. Multiple child-bearing is a norm in most part of South Sudan, and in some cases, child bearing does not stop in an individual until menopause. The younger age bracket having the highest proportion in this study may be a factor for having mothers with 'not too high' number of children, considering the fact that they are still at their low reproductive ages. There exists a high probability for them to give birth to a greater number of children in the nearest future, in tandem with their culture.

\subsection{Mothers'/Guides' Knowledge on Immunization}

This study revealed that approximately $72 \%$ of the mothers/guides have good knowledge of immunization, and there are close to one-third of them $(27.9 \%)$ with poor knowledge about immunization. The proportion of mothers/guides having good knowledge on immunization in this study appeared better than the result of a similar study conducted in Addis-Ababa in Ethiopia by Birhanu et al in 2016 [12], which showed that only 55\% of the mothers had good knowledge on immunization. This implies that about $45 \%$ of mothers in their study had poor knowledge on immunization. This is equally supported by Ramadan et al in 2016 [13] in another similar study conducted in Damietta Governorate in Egypt which results revealed $44 \%$ of the mothers having poor knowledge on immunization. The high proportion of respondents with good knowledge on immunization in this study may be associated with the concerted efforts galvanized by UNICEF, WHO and other implementing partners on routine immunization health education given to the pregnant women during the Antenatal clinic, mothers at immunization clinics coupled with the possible social mobilization projects embarked upon by various health implementing partners like Community Health And Development Organization (CHADO), a local NGO which implements this service for UNICEF in Lakes state. However, the close to one-third proportion of mothers/guide with poor knowledge on immunization points to the fact that, there is still a gap in the awareness/health education programs embarked upon regarding immunization in the county. There is every possibility for the innocent children of such mothers with poor knowledge on immunization to experience missed opportunities to get vaccinated due to poor knowledge of the mother.

\subsection{Attitudes Towards Immunization}

In this study, it was revealed that slightly above half $(52.9 \%)$ of the mothers/guides have good attitude towards immunization, while a considerably high proportion of $47.1 \%$ of them have poor attitude towards immunization. The proportion of mothers/guides with good attitude in this study is in close concordant with the results of the study conducted in Addiss Abbaba by Birhanu et al [12], which revealed $53.8 \%$ of the mothers in their study had positive attitude towards immunization of their children. However, the result of this study in this regard is in slight variance with the results of the study conducted in Egypt by Ramadan et al [13] which reported $70 \%$ of the mothers having good attitude towards immunization, which is a considerably higher percentage than the proportion obtained in this study. Various geo-political reasons may be responsible for the fairly better results in the study conducted in Egypt over that of the present study in South Sudan.

The average proportion of mothers/guides with good attitude towards immunization in this study is not in adequate 
enough to cancel the negative influence of the high proportion of them with poor attitude. This implies that even though around half of the mothers/guides have good attitudes towards immunization, the close to half proportion of them having poor attitude towards immunization is enough to serve as an indispensable factor for the possible increasing rate of missed opportunities and incomplete vaccination of the children in Rumbek Centre County. It is a known fact that even though an individual has a good knowledge about a beneficial service but shows poor attitude towards accessing the service, then the expected outcome (impact) will not be achieved because accessing the service will be precluded by the poor attitude of the responsible person. This is purely applicable in this context.

It then implies that all stakeholders responsible for the child health services in the Runbek Centre County especially, and Lakes state in general, should spur up actions towards ensuring a paradigm shift in addressing the high proportion of the mothers/guides with poor attitudes towards immunization, in order to halt the anticipated trend of silent missed opportunities for children to get vaccinated and the high probability for many children to have incomplete vaccination in Rumbek Centre County and possibly in the whole of Lakes state, as a result of many mothers'/guides' poor attitudes towards immunization.

\subsection{Association Between Knowledge on Immunization and Respondents'Socio-demographic Variables}

The results of this study revealed that marital status, level of education, occupation and number of children are found to have statistically significant association $(\mathrm{P}<0.05)$ with the knowledge of mothers/guides, while age and religion do not have statistically significant association $(\mathrm{P}>0.05)$ with the knowledge of the respondents. This partly agrees with the study results of Birhanu et al [12] which stated that mothers' education and number of children have statistically significant association with the knowledge of mothers on immunization. It also partly disagrees with the study outcome of Ramadan et al [13] which stated that age was found to be statistically correlated with the mothers' knowledge in their study. According to the outcome of this study, it implies that marital status, level of education, occupation and number of children are predicting factors in determining the knowledge of mothers/guides on immunization. For example, a married woman has a probable tendency to be supported by her husband regarding getting their child/children vaccinated and vice versa, while an illiterate married woman may have high tendency to be confined to a poor knowledge corner about immunization due to her zero level of education. This can also be confirmed in this study as very high proportion of the mothers/guides has no formal education.

\subsection{Association Between Attitudes Towards Immunization and Respondents'Socio-demographic Variables}

As revealed in the results of this study, marital status, religion, level of education and occupation have statistically significant association $(\mathrm{P}<0.05)$ with the attitude of the mothers/guides. Both age and number of children were not found to have any statistically significant association $(\mathrm{P}>0.05)$ with the mothers'/guides' attitudes towards immunization. In a close related study conducted by Awodele et al in 2010 [14] in Lagos Nigeria, the result of the study showed that there were significant relationships between age of respondents, level of education, occupation and attitude to immunization. However, there was no significant relationship between religion and attitude to immunization $(\mathrm{P}>0.05)$. Age is the only socio-demographic variable considered not to be in agreement with the outcome of this study, as it was found not to have statistically significant association with the respondents' attitude in this study in opposition to the Awodele et al [14], which stated otherwise.

It is then in order to opine that marital status, religion, level of education and occupation are predicting factors in determining the attitude of the mothers/guides towards immunization in Rumbek Centre County. It can be explained thus for example; an educated woman may have an advantage of developing good attitude towards immunization than an illiterate woman, because the process of imbibing good attitude towards immunization may be catalysed by the advantageous level of education. A married woman may be assisted or prevented by the husband to develop a good attitude towards immunization, depending on the perception of the husband towards the importance of immunization, and in the same vein, a woman who is home-ridden (as house wife by occupation) may develop a negative attitude towards immunization because of her social confinement and low exposure. Hence, the crusaders of immunization in Rumbek Centre County should develop a road map towards addressing these predicting factors, in a direction to at least reduce the possibility of continuous missed opportunities for vaccination and incomplete vaccination of this vulnerable population.

\subsection{Vaccine Compliance of the Respondents' Children}

Considering the basic but important vaccines received by children in South Sudan, at different ages (BCG, OPV, Pentavalent and Measles vaccines), the results of this study showed mixed revelations that are of good interest and in concordance with the other results. For BCG and OP1 vaccines, which are normally given to infants at birth, $73 \%$ of the respondents' children due for the vaccination as at the study period, received the two vaccines at the appropriate time, $20 \%$ of them received late and $7 \%$ had not received the vaccine. The results regarding Penta1 and OPV1 vaccines revealed that $70 \%$ of the children due by age as at the study period, received the vaccines at the right time, $17 \%$ received late while $13 \%$ did not received the vaccines. In furtherance to the foregoing, only $37 \%$ of the children due for the Penta 3 and OPV3 vaccines received them at the right time, $14 \%$ received late and almost half of the children did not receive the two vaccines as at the study period, even though they are due by age to receive the third doses of Pentavalent and OPV. It can be seen that there was a sharp difference between the 
Penta1/OPV1 and Penta3/OPV3 $(70 \%+17 \%=87 \%$, as the total number of children who received Penta1 at the right time or late) to $(39 \%+14 \%=53 \%$ as total number of children who received Penta3 early or late). An adaptable drop-out rate on this can be estimated as $87 \%-53 \%=34 \%$ drop-out rate. This is at variance with the principle of primary health care as regards immunization of children because any drop-out rate above $10 \%$ is considered unacceptable. This implies that if the drop-out rate for Pentavalent vaccines in Rumbek Centre County is $34 \%$, then it is a worrisome situation and all stakeholders in child health must answer to a clarion call to salvage the situation.

The result of vaccine compliance of measles vaccine was another interesting one, as it showed that only $29 \%$ of the children qualified to have been vaccinated with measles vaccine as at the study period received the vaccine at the right time, $4 \%$ received late and over two-third (67\%) did not receive measles vaccine. Outbreak of measles in this type of situation should not be a surprise as it is difficult to achieve herd immunity among the children in such population, consequent to the high proportion of children who have not received measles vaccination and are due or over due by age for it. The situation regarding the vaccine compliance generally demands 'all hands to be on deck' in Rumbek Centre County to ameliorate the situation.

In a related study in Vietnam (published in 2018) which investigated the progress of the timeliness of childhood immunization compliance among children between $0-5$ years of age from 2006 to 2014 and analyzed the socio-economic factors that account for the changes of the compliance rate during this period. It was revealed in their study that the progress of the timeliness of childhood immunization has been positive and the major contribution comes from the structure/unmeasured effect. Rural areas show a stronger improvement as of 2014. Among the socio-economic factors, mother education and birth order are the ones that have the larger influence on the childhood immunization compliance rate [15]. This is at variance with the outcome of this present study and the possible reason can be associated with the socio-cultural factors and low mothers'/guides' education which are still negatively affecting the efficacy of the immunization programme in Rumbek Centre County and South Sudan generally.

\subsection{Conclusion}

Although this study showed high proportion of mothers/guides with good knowledge on immunization coupled with only around average proportion of them with good attitude, the proportions of women with poor knowledge and attitude in Rumbek Centre County still remain a source of concern and demands attention from all health stakeholders. The various socio-demographic variables of the mothers/guides like marital status, level of education and occupation which are commonly found to be statistically significantly associated with both knowledge and attitude of mothers/guides towards immunization of their children, are pointers to the possible next line of actions to be taken by all stakeholders in that regard. The present negative trends in the vaccine compliance of various antigens (BCG, OPV, Pentavalent and Measles), in this study is a performancefeedback of the indicators to be improved upon in the Expanded Program on Immunization (EPI) in Rumbek Centre County.

\section{References}

[1] Rainey JJ, Watkins M, Ryman TK, Sandhu P, Bo A, Banerjee K. (2011) Reasons related to non-vaccination and undervaccination of children in low and middle income countries: findings from a systematic review of the published literature, 1999-2009. Vaccine. 2011 Oct 26; 29 (46): 8215-21. doi: 10.1016/j.vaccine.2011.08.096. Epub 2011 Sep 3.

[2] Favin, L. T., Jackson, D., Engebretsen, I. M., Zembe, W., Sanders, D., Sommerfelt, H., and Tylleskar, T. (2011). Vaccination coverage and timelines in South African areas: a prospective study. BMC Public Health, 11 (1) 1. http://doi.org/10.11.1186/1471-2458-11-404.

[3] World Health Organization- WHO (2011): Global routine immunization coverage.

[4] Funmilayo, A. (2013). Determinants of Full Child Immunization among 12-23 months old in Nigeria. Retrieved June 23, 2016 from http://paa2013.princeton.edu/abstracts/131634.

[5] Kenya Demographic Health Survey- KDHS (2008/2009).

[6] Thaddaeus Egondi, Maharouf Oyolola Martin K Mutua, Patricia Elungata (2015: Determinants of immunization inequality among urban poor children: Evidence from Nairobi's informal settlements International Journal for Equity in Health 14 (1) DOI: 10.1186/s12939-015-0154-2.

[7] World Health Organization (2013): Expanded Program on Immunization.

[8] United Nation Development Program- UNDP (2013): Annual Report on immunization.

[9] World Health Organization Report- WHO (2014): Comparing static and outreach immunization.

[10] Trepo C. G., Stevens C. E., Szmuness W (2014): Prevention of hepatitis B infections by passive immunization. Ricerca in clinica e in laboratorio, Volume 7, Issue 3, pp 198-208|.

[11] Maina, L. C., Karanja, S., Kombich, J. (2013). Immunization Compliance and its determinants among children aged 12-23 months in a peri-urban area of Kenya. The Pan African.

[12] Frehiwot Birhanu, Asrat Meleko, Mesfin Geremew (2016): Assessment of Child Immunization Coverage and Associated Factors with Full Vaccination among Children Aged 12-23 Months at Mizan Aman Town, Bench Maji Zone, Southwest Ethiopia. International Journal of Pediatrics Volume 2017 (Article ID 7976587): 11 pages DOI: 10.1155/2017/7976587.

[13] Ramadan H. A, Soliman S. M, Abd El-kader R. G (2016): Knowledge, Attitude and Practice of Mothers toward Children's Obligatory Vaccination. Journal of clinical sciences vol 16 issue $1 \mathrm{pg} 7-14$. 
[14] Awodele O, Oreagba I. A, Akinyede A D. F. Awodele Dolapo D. C (2010): The knowledge and attitude towards childhood immunization among mothers attending antenatal clinic in Lagos University Teaching Hospital, Nigeria. Tanzania journal of Health research vol 12i3. 51112.
[15] Huong Trinh Thi1, Thuy DO THI THUY, Christine THOMAS-AGNAN, Quang Dung NGUYEN and Huy NGUYEN VAN (2018): Measuring the progress of the timeliness childhood immunization compliance in Vietnam between 2006-2014: A decomposition analysis. 